Departamento de Química Orgânica e Biológica

Faculdade de Medicina Veterinária da Universidade de São Paulo Diretor - Prof. Dr. Fonseca Ribeiro

\title{
DOSEAMENTO DE ÁCIDO ASCÓRBICO EM VEGETAIS SULFATADOS
}

\author{
POR \\ O. F. Ribeiro \\ Preparador de Química Tecnológica Inorgânica \\ - Química Tecnicológica Orgânica da Escola \\ Politécnica de São Paulo
}

Sendo o ácido ascórbico extraordinariamente sensivel à ação catalítica oxidante do cobre é de se indagar a possivel influência desse metal no doseamento de vitamina $C$ em vegetais que são normalmente tratados pelo sulfato de cobre, visto que fica sempre na superfície dos mesmos um depósito maior ou menor do sal. $\mathrm{Na}$ operação de doseamento esse depósito de cobre da superficie obrigatoriamente contamina o extrato e poderia assim representar uma causa de erro.

Dentre as frutas que no nosso meio são quasi que sistematicamente "sulfatadas» destacam-se o figo e a uva.

Doseando o cobre nestas duas variedades vegetais encontramos em média: uva 0,4 mgr. e figo $0,9 \mathrm{mgr}$. para 100,0 gr. de substância, portanto valores que não deveriam ser negligenciados. Agradecemos ao Sr. José Galeano o auxilio que nos prestou nesse doseamento de cobre.

\section{EXPERIMENTAÇÃO}

Uma solução titulada de ácido ascórbico é acrescida de $2 \mathrm{mgr}$. de cobre em cada $100 \mathrm{~cm}^{3}$ e após exatamente 10 minutos de contato tratada por solução de ácido metafosfórico a $3 \%$ na proporção de $1: 2$, conforme a sequência do doseamento de ácido ascórbico nos vegetais. Após a adição de $\mathrm{HPO}_{3}$ a mistura permanece por tempos variaveis de $5,10,15,20$ e 25 minutos para então se fazer a passagem de uma corrente de $\mathrm{H}_{2} \mathrm{~S}$ e no dia imediato, depois da eliminação do gás sulfídrico pelo $\mathrm{CO}_{2}$, procede-se a titulação. Visto que no doseamento em vegetais depois da adição de $\mathrm{HPO}_{3}$ sempre se necessita esperar alguns minutos (filtração, centrifugação, etc.) até que o extrato receba $\mathrm{o} \mathrm{H}_{2} \mathrm{~S}$, fizemos em duplicata a prova acima referida usando a solução de $\mathrm{HPO}_{3}$ na qual se passara anteriormente $\mathrm{H}_{2} \mathrm{~S}$.

Os tubos $1,3,5,7$ e 9 receberam $\mathrm{HPO}_{3}$, depois de 10 minutos de contato do cobre com a solução de ácido ascórbico e a corrente de $\mathrm{H}_{2} \mathrm{~S}$ foi passada em tempos respetivos de $5,10,15,20$ e 25 minutos. Idem, para os tubos 2, 4, 6, 8 e 10 que ao envés de $\mathrm{HPO}_{3}$ receberam, 


\begin{tabular}{c|c}
\hline Tubos & Ácido ascórbico \\
\hline \hline & $\%$ \\
1 & 24,4 \\
2 & 24,3 \\
3 & 24,3 \\
4 & 24,2 \\
5 & 24,7 \\
6 & 24,9 \\
7 & 24,5 \\
8 & 24,3 \\
9 & 24,3 \\
10 & 24,4 \\
Testemunho & 23,1 \\
\hline
\end{tabular}

nas condições anteriores, o ácido metafosfórico já saturado pelo $\mathrm{H}_{2} \mathrm{~S}$ e posteriormente, nos mesmos intervalos de tempo tambem a corrente de gás sulfídrico. Nota-se nestes resultados a igualdade de valores o que demonstra a reversibilidade da possivel oxidação do ácido ascórbico pelo cobre, nas condições de tempo da experiência. $\mathrm{O}$ valor ligeiramente inferior do testemunho deve ser atribuido a uma pequena quantidade de ácido deidroascórbico já existente na solução do ácido cevitâmico (autoxidação). Observa-se tambem que não houve diferença entre os resultados dos tubos que receberam $\mathrm{HPO}_{3}$ e os que receberam a solução desse ácido já saturada pelo $\mathrm{H}_{2} \mathrm{~S}$.

Em outra prova procuramos indagar a influência do tempo entre a adição de cobre e a acidificação pelo ácido metafosfórico não estendendo esse tempo alem de 50 minutos por não ser necessário nos processos de doseamento de ácido ascórbico em extratos vegetais.

QUADRO N.० 1

Efeito inibidor do $\mathrm{HPO}_{8}$ na oxidação catalítica do ácido ascórbico pelo cobre

\begin{tabular}{|c|c|c|c|c|}
\hline \multirow{2}{*}{ Tubos } & \multirow{2}{*}{ Tempo } & \multicolumn{2}{|c|}{$\begin{array}{l}\text { Acido ascórbico }- \text { mgr. } \% \\
\text { antes do } \mathrm{H}_{2} \mathrm{~S}\end{array}$} & \multirow{2}{*}{$\begin{array}{c}\text { Ácldo ascórbi- } \\
\text { co - mgr. } \% \\
\text { apos } \mathrm{H}_{2} \mathrm{~S}\end{array}$} \\
\hline & & $\begin{array}{c}\text { Acidificação em } \\
\text { tempo zero }\end{array}$ & $\begin{array}{l}\text { Acidif. no momento } \\
\text { de reduzir pelo } \mathrm{H}_{2} \mathrm{~S}\end{array}$ & \\
\hline$T$ & - & - & - & 9,87 \\
\hline $\mathrm{T}^{1}$ & $0 \mathrm{~min}$ & 9,83 & - & 9,86 \\
\hline 1 & 10 & 9,81 & - & 9,86 \\
\hline 2 & $10 *$ & - & 7,66 & 9,91 \\
\hline 3 & 20, & 9,74 & - & 9,90 \\
\hline 4 & 20 & - & 7,02 & 9,85 \\
\hline 5 & 30 , & 9,76 & - & 9,89 \\
\hline 6 & 30 , & - & 6,03 & 9,83 \\
\hline 7 & 40 . & 9,76 & - & 9,90 \\
\hline 8 & 40, & - & 5,76 & 9,84 \\
\hline 9 & 50 , & 9,75 & - & 9,88 \\
\hline 10 & $50 \times$ & - & 5,31 & 9,84 \\
\hline
\end{tabular}


Observa-se claramente que após a acidificação pelo $\mathrm{HPO}_{3}$ o cobre não faz sentir sua ação catalítica $\left({ }^{*}\right)$ ou o faz apenas em proporções mínimas $(0,8 \%)$ enquanto que na ausência do ácido a oxidação atingiu a $45,9 \%$ no espaço de 50 minutos, embora fosse integralmente reversivel.

Outro detalhe que se poderia considerar era o da variação da quantidade de cobre e tambem aquí, no espaço de 50 minutos a partir do momento em que se juntou o cobre, a transformação de ácido ascórbico em deidro foi reversivel pelo $\mathrm{H}_{2} \mathrm{~S}$.

Os resultados seguintes expressam a média dos resultados:

\begin{tabular}{c|c|c}
\hline Tubos & $\begin{array}{c}\text { Cobre } \\
\text { mgr. em 100 cm.s } \\
\text { de soluç̄on }\end{array}$ & $\begin{array}{c}\text { Ácido ascórbico } \\
\text { Recuperado } \\
\text { mgr. \%\% }\end{array}$ \\
\hline \hline 1 & - & 6,44 \\
2 & 0,5 & 6,45 \\
3 & 1,0 & 6,38 \\
4 & 1,5 & 6,41 \\
5 & 2,0 & 6,34 \\
\hline
\end{tabular}

O conjunto dos resultados indica claramente que a ação oxidante do cobre não interfere no doseamento do ácido ascórbico ao menos quando se faz, dentro de 50 minutos, a redução pelo $\mathrm{H}_{2} \mathrm{~S}$.

Em uma série de exames em uvas nacionais utilizamo-nos do processo de TAuber e KLeiker (3) modificado por Leser (4):

1) obtenção de $10 \mathrm{~cm}^{3}$ de caldo de uva por expressão e filtração;

2) adição de $20 \mathrm{~cm}^{3}$ de ácido metafosfórico a $3 \%$;

3) adaptação de $\mathrm{pH} \pm 6$, em $10 \mathrm{~cm}^{3}$ da mistura por meio de $1 \mathrm{~cm}^{3}$ de solução $\mathrm{N} / 2$ de $\mathrm{CO}_{3} \mathrm{Na}_{2}$;

4) passagem da corrente de $\mathrm{H}_{2} \mathrm{~S}$ por 5 minutos e conservação do recipiente fechado e na obscuridade por 12 horas;

5) eliminação do $\mathrm{H}_{2} \mathrm{~S}$ por meio de $\mathrm{CO}_{2}$ até ausência de reação com o papel de acetato de chumbo;

6) doseamento pelo 2-6, diclorofenolindofenol. (Resultado A);

7) destruição do ácido ascórbico pela ascorbinase (preparada segundo Fugita e SaKamoto (5). (Resultado B).

NOTA: O ácido ascórbico real é calculado da diferença de A e B.

(*) Já em 1936 MUSULIN e KINO (1) demonstraram que se trata de um efeito específico do $\mathrm{HPO}_{3}$ e nåo de uma simples questão de pH e posteriormente LYMAN, SCHULTZE e KINO(2) adicionam novos detalhes a respeito. 
QUADRO N.० 2

Teor em ácido ascórbico de uvas nacionais

\begin{tabular}{|c|c|c|c|c|c|c|}
\hline & \multicolumn{3}{|c|}{ U V A B R A N C A } & \multicolumn{3}{|c|}{ U V A P RETA } \\
\hline & 1 & 2 & 3 & 4 & 5 & 6 \\
\hline & $\begin{array}{c}\text { Após } \mathrm{CO}_{2} \\
\text { mgr. } \% \%_{0}\end{array}$ & $\begin{array}{c}\text { Resto } \\
\text { mgr. \% }\end{array}$ & $\begin{array}{c}\text { Real } \\
\text { mgr. } \%\end{array}$ & $\begin{array}{c}\text { Após } \mathrm{CO}_{3} \\
\text { mgr. } \%\end{array}$ & $\begin{array}{c}\begin{array}{c}\text { Resto } \\
\text { mgr. \% }\end{array} \\
\end{array}$ & $\begin{array}{c}\text { Real } \\
\text { mgr. } \%\end{array}$ \\
\hline $\begin{array}{r}1 \\
2 \\
3 \\
4 \\
5 \\
6 \\
7 \\
8 \\
9 \\
10 \\
11 \\
12 \\
13 \\
14 \\
15 \\
16 \\
17 \\
18 \\
19 \\
20 \\
21 \\
22 \\
23 \\
24 \\
25 \\
26 \\
27 \\
28 \\
29 \\
30\end{array}$ & $\begin{array}{l}8,74 \\
8,05 \\
6,47 \\
7,87 \\
6,62 \\
8,51 \\
7,57 \\
7,65 \\
7,69 \\
9,47 \\
7,87 \\
6,82 \\
5,60 \\
7,87 \\
6,82 \\
6,82 \\
9,47 \\
8,39 \\
8,39 \\
8,05 \\
5,42 \\
4,55 \\
4,37 \\
6,12 \\
5,42 \\
6,82 \\
5,78 \\
6,30 \\
7,12 \\
7,00\end{array}$ & $\begin{array}{l}0,87 \\
0,87 \\
0,00 \\
0,00 \\
0,00 \\
0,52 \\
0,87 \\
0,00 \\
1,75 \\
0,87 \\
1,40 \\
0,87 \\
1,40 \\
1,40 \\
0,87 \\
1,40 \\
1,75 \\
1,40 \\
1,40 \\
1,40 \\
1,40 \\
0,70 \\
0,70 \\
0,87 \\
1,40 \\
1,40 \\
1,75 \\
0,70 \\
0,87 \\
0,70\end{array}$ & $\begin{array}{l}7,87 \\
7,18 \\
6,47 \\
7,87 \\
6,62 \\
7,99 \\
6,70 \\
7,65 \\
6,94 \\
8,60 \\
6,47 \\
5,95 \\
4,20 \\
6,47 \\
5,95 \\
5,42 \\
7,72 \\
6,99 \\
6,99 \\
6,65 \\
4,02 \\
3,85 \\
3,67 \\
5,25 \\
4,02 \\
5,42 \\
5,03 \\
5,60 \\
6,25 \\
6,30\end{array}$ & $\begin{array}{l}6,65 \\
8,22 \\
5,95 \\
9,44 \\
5,25 \\
5,25 \\
5,07 \\
4,90 \\
5,42 \\
4,37 \\
6,65 \\
6,82 \\
4,65 \\
4,37 \\
5,42 \\
5,60 \\
9,10 \\
5,25 \\
7,22 \\
5,07 \\
4,20 \\
3,50 \\
3,50 \\
4,20 \\
4,20 \\
4,39 \\
3,90 \\
4,55 \\
4,20 \\
4,55\end{array}$ & $\begin{array}{l}0,70 \\
0,87 \\
0,70 \\
0,80 \\
0,52 \\
0,87 \\
0,70 \\
0,52 \\
0,70 \\
0,52 \\
1,40 \\
1,75 \\
1,40 \\
0,87 \\
1,92 \\
0,37 \\
0,87 \\
1,10 \\
1,40 \\
1,40 \\
0,70 \\
0,35 \\
0,17 \\
0,37 \\
0,70 \\
0,87 \\
1,40 \\
0,70 \\
0,87 \\
0,87\end{array}$ & $\begin{array}{l}5,95 \\
7,35 \\
5,25 \\
8,57 \\
4,73 \\
4,28 \\
4,37 \\
4,38 \\
4,72 \\
3,85 \\
5,25 \\
5,07 \\
3,25 \\
3,50 \\
3,50 \\
4,73 \\
8,23 \\
4,15 \\
5,82 \\
3,67 \\
3,50 \\
3,15 \\
3,33 \\
3,33 \\
3,50 \\
3,52 \\
2,50 \\
3,75 \\
3,33 \\
3,68\end{array}$ \\
\hline 30 & $\begin{array}{l}M=7,12 \\
\sigma=1,29 \\
V=18,1 \%\end{array}$ & $\begin{array}{l}M=0,98 \\
\sigma=0,52 \\
\mathrm{~V}=53,1 \%\end{array}$ & $\begin{array}{l}M=6,20 \\
\sigma=1,28 \\
V=20,6 \%\end{array}$ & $\begin{array}{l}M=5,40 \\
\sigma=1,55 \\
\mathrm{~V}=28,7 \%\end{array}$ & $\begin{array}{l}M=0,92 \\
\sigma=0,39 \\
V=42,4 \%\end{array}$ & $\begin{array}{l}M=4,47 \\
\sigma=1,45 \\
\mathrm{~V}=32,4 \%\end{array}$ \\
\hline
\end{tabular}

Da análise estatística que segue ver-se-á que as diferenças existentes entre as duas variedades de uva independem do acaso, já o mesmo não acontecendo com as substâncias interferentes não ácidoascórbico (colunas 2 e 5 ).

$$
\begin{aligned}
& \begin{aligned}
\text { Dif. entre } 1 \text { e } 4 & =1,72 \\
\sigma d & =0,37
\end{aligned} \frac{\mathrm{d}}{\sigma \mathrm{d}}=\frac{1,72}{0,37}=4,6 \\
& \begin{aligned}
\text { Dif. entre } 2 \text { e } 5 & =0,06 \\
\sigma \mathrm{d} & =0,38
\end{aligned} \mid \frac{\mathrm{d}}{\sigma \mathrm{d}}=\frac{0,06}{0,38}=0,2 \\
& \begin{aligned}
\text { Dif. entre } 3 \text { e } 6 & =1,73 \\
\sigma \mathrm{d} & =0,35
\end{aligned} \mid \frac{\mathrm{d}}{\sigma \mathrm{d}}=\frac{1,73}{0,35}=4,9
\end{aligned}
$$




\section{RESUMO}

O autor demonstra que a existência de sais de cobre na superfície de vegetais que sofreram "sulfatação» não representa causa de erro no doseamento de ácido ascórbico pelo método de TAUBER e KLEINER modificado por LESER; as provas em amostras de uvas nacionais deram em média os seguintes resultados: uva branca $6,20 \%$; uva preta $4,47 \%$ (mgr. de ácido ascórbico por $100 \mathrm{~cm}^{3}$ do caldo da fruta).

\section{BIBLIOGRAFIA}

1) Musulin, R. R. - King, G. G. - 1936 - Jour. Biol, Chem, 116:409.

2) Lyman, C. M. - Schultze, M. O. - King, G. G. - 1937 - Jour. Biol. Chem., 118:757.

3) Tauber, H. - Kleiner, I. - 1935 - Jour. Biol. Chem., 110:559.

4) Leser, W. P. - Informação Pessoal.

5) Fuorta A. - Sакамото, T. - 1938 - Biochem. Z., 297:10. 